\title{
Correction to: Risk Assessment of Infection by Airborne Droplets and Aerosols at Different Levels of Cardiovascular Activity
}

\author{
Jana Wedel $^{1} \cdot$ Paul Steinmann $^{1,2}$ (1) $\cdot$ Mitja Štrakl $\left.\right|^{3} \cdot$ Matjaž Hriberšek $^{3} \cdot$ Jure Ravnik $^{3}$ \\ Published online: 15 December 2021 \\ (c) CIMNE, Barcelona, Spain 2021 \\ Correction to: \\ Archives of Computational Methods in Engineering \\ (2021) 28:4297-4316 \\ https://doi.org/10.1007/s11831-021-09613-7
}

Incorrect versions of Figs. 8, 11, 12, 13 and 14 were published due to wrong version of file used by typesetter.

Original article has been corrected with the correct version.

Publisher's Note Springer Nature remains neutral with regard to jurisdictional claims in published maps and institutional affiliations.

The original article can be found online at https://doi.org/10.1007/ s11831-021-09613-7.

Jana Wedel

jana.wedel@fau.de

Paul Steinmann

paul.steinmann@fau.de

Mitja Štrakl

mitja.strak1@gmail.com

Matjaž Hriberšek

matjaz.hribersek@um.si

Jure Ravnik

jure.ravnik@um.si

1 Institute of Applied Mechanics, University of ErlangenNuremberg, Erlangen, Germany

2 Glasgow Computational Engineering Center, University of Glasgow, Glasgow, UK

3 Faculty of Mechanical Engineering, University of Maribor, Maribor, Slovenia 